\title{
Utility of an Epidural Pressure Checker in the Administration of Trans-Laminar Epidural Blocks
}

\author{
Nam Lee ${ }^{1 *}$, Sam Sun Park²*, Gyu Yeul Ji ${ }^{2}$, Byeong Woo Kim², Chang Kyu Lee ${ }^{2}$, Eui Chul Kim², \\ Dong Ah Shin ${ }^{2 \otimes}$ \\ ${ }^{1}$ Department of Neurosurgery, Dong-Eui Medical Center, Busan, Korea \\ ${ }^{2}$ Department of Neurosurgery, Spine and Spinal Cord Institute, Yonsei University College of Medicine, Seoul, Korea
}

\begin{abstract}
Objective: Loss of resistance technique has been performed to identify the epidural space. However, this technique has some disadvantages including frequent lack of midline ligamentum flavum, erroneous subjective sensing, and higher failure rate. The aims of this study were to identify the optimal negative pressure representing the epidural space and to evaluate the efficacy of an epidural pressure checker to detect the epidural space. Methods: Ninety-six patients who received a trans-laminar epidural block in the spine at our institute were enrolled. Half of them received a cervical epidural block (cervical group) and the other half received a lumbar epidural block (lumbar group). Patients were randomly assigned to one of the set pressure groups $(-8,-7,-6,-5,-4,-3$ mbar). When the needle penetrated the ligamentum flavum, the epidural pressure checker detected negative pressure at the epidural space and alarmed with sound and light if the pressure detected was below the set pressure. Results: In the cervical group, detection rates were $62.5 \%, 75 \%, 75 \%$ at set pressure values of $-8,-7,-6 \mathrm{mbar}$, respectively, and $87.5 \%$ at $-5 \mathrm{mbar}$. In the lumbar group, rates were $50 \%, 62.5 \%, 62.5 \%$ at set pressure values of $-8,-7,-6 \mathrm{mbar}$, respectively, and $87.5 \%$ at $-5 \mathrm{mbar}$. False positives were frequent below a set pressure of $-4 \mathrm{mbar}$. Conclusion: The optimal pressure value to detect the epidural space was -5 mbar. The epidural pressure checker may be a reliable, easy and useful tool to aid in the administration of a trans-laminar epidural block.
\end{abstract}

Key Words: Epidural space; Pressure; Measurement; Epidural block; Epidural anesthesia.

ه Corresponding author: Dong Ah Shin, Department of Neurosurgery, Spine and Spinal Cord Institute, Yonsei University College of Medicine, 50 Yonsei-ro, Seodaemun-gu, Seoul 03722, Korea. Tel: 82-2-2228-2150, Fax: 82-2-393-9979, E-mail: shindongah@me.com

*These two authors contributed equally.

\section{INTRODUCTION}

Lower back pain (LBP) is one of the most common diseases in adults. The cumulative lifetime prevalence of LBP lasting at least two weeks is $13.8^{-30} \%^{1,2,4)}$. In addition, $70-85 \%$ of all people have back pain at some time in their life ${ }^{1)}$. Posterior axial neck pain is also common and the average annual incidence rate for cervical radiculopathy is 83.2 per $100000^{13)}$.

An epidural block is an interventional pain management procedure used to treat spinal pain. This procedure was introduced in 1952 by Robecchiet al. and its usefulness has been reported by many previous investigators ${ }^{5,10,14)}$. Definitive identification of the epidural space is essential for achieving a successful epidural block. The loss of resistance (LOR) technique, the most commonly used method to identify the epidural space, was introduced by Sicard and Forestier in $1921^{16)}$. This procedure is conducted by applying pressure to the plunger using one's thumb. Howev- er, this method has some disadvantages. A clear loss of resistance may not be felt in patients with an abnormal ligamentumflavum ${ }^{9)}$. In addition, Zarzuret al. reported that there is no naturally occurring negative pressure that leads to a loss of resistance in the epidural space ${ }^{21)}$. These limitations may result in unintended puncture of the dura, spinal cord injury or epi/subdural hematoma ${ }^{12,17)}$. A dural puncture and leakage of cerebrospinal fluid (CSF) are the most common complications of an epidural block ${ }^{3)}$. It can cause a post-dural puncture headache, requiring that the patient be treated with bed rest, fluid therapy and hospitalization ${ }^{8)}$.

In order to avoid these complications and enhance the safety and accuracy of this procedure, an epidural pressure checker (Epi-check, Silimed, Bucheon, Korea) was designed. The aim of this study was to identify the optimal negative pressure representing the epidural space in both the cervical and lumbar spine and to evaluate the accuracy of Epidural pressure checker 
in detecting the epidural space.

\section{MATERIALS AND METHODS}

Institutional review board approval was obtained before initiating this study. From October 2013 to October 2014, 96 patients who underwent trans-laminar epidural blockade of the cervical or lumbar spine at our institute were enrolled. Half of the enrolled patients (48 patients) received a cervical epidural block (cervical group) and the remaining half (48 patients) received a lumbar epidural block (lumbar group). All patients complained of axial pain with/without radiating pain in their extremities and showed mild to moderate degenerative spondylosis of their spine on MRI. All enrolled patients had spinal pain refractory to conservative therapy, which included medications and/or physical therapy for the first four to six weeks. We excluded patients taking Coumadin and those with systemic disease, severe obesity (body mass index $>35 \mathrm{~kg} / \mathrm{m}^{2}$ ) or infection.

\section{Epidural pressure checker}

The epidural pressure checker was designed to detect the epidural space exactly by perceiving the pressure shift to a negative value. This device is composed of a printed circuit board (PCB) containing a micro-electro mechanical system (MEM) pressure sensor and polycarbonate spouting that connects to a Tuohy needle (Fig. 1). The allowable error of the device ranges was from -0.5 mbar to +0.5 mbar. When a Tuohy needle connected to the epidural pressure checker penetrates the ligamentum flavum and encounters the epidural space, the negative pressure of the epidural space is transferred to the epidural pressure checker via the inner cannula of the needle. The epidural pressure checker then perceives the negative pressure with a pre-set pressure threshold and alarms with sound and light. The concept underlying the design of this device is that a specific area of the human body exists as a vacuum with no pressure shift such that the digital sensor recognizes the pressure shift between the ligamentum flavum and the epidural space.

\section{Trans-laminar epidural block}

Blood pressure, cardiac activity (EKG), oxygen saturation and

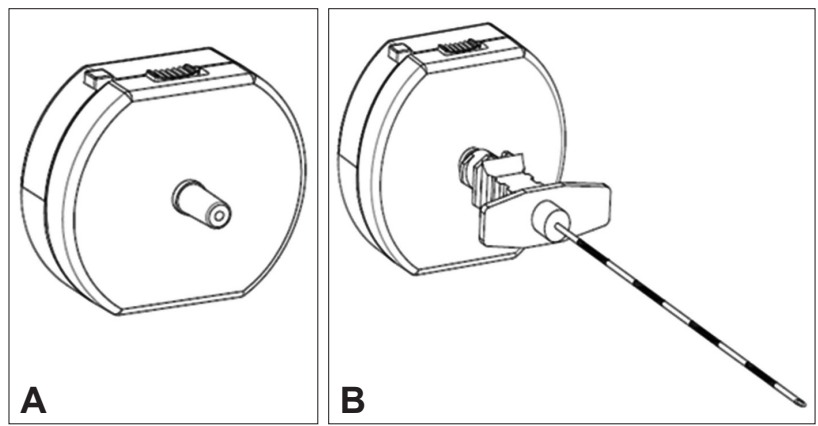

Fig. 1. The Epidural pressure checker is composed of a printed circuit board (PCB) containing a micro-electro mechanical system (MEM) pressure sensor and polycarbonate spouting designed to connect to a Touhy needle. Epi-check (A) connected to a Touhy needle (B). pulse rate were monitored during the procedure. Patients were placed in a prone position on the table and their skin was prepared in a normal manner. All procedure was undergone with prone position in both cervical and lumbar epidural block. Because the sitting or lateral decubitus position can affect the epidural pressure, we decided that all procedure was undergone in same position. A $20 \mathrm{G}, 10$-cm-long Tuohy needle was introduced within the midline at the level of the interspinous ligament under C-arm fluoroscopy guidance. Once the needle tip met the spinous-laminar line, the trocar was removed and the epidural pressure checker was connected (Fig. 2). The Tuohy needle was advanced slightly and the epidural pressure checker detected a pressure drop based on preset values of -8 mbar to -3 mbar. It alarmed with sound and lights when the pressure dropped under the pre-set pressure value. Once the epidural pressure checker alarmed, we injected $3 \mathrm{~mL}$ of Omnipaque 300 (GE healthcare AS, Ireland) through the needle to confirm the needle was in the epidural space under C-arm fluoroscopy. If the epidural pressure checker did not alarm, but the needle tip was found to be located in the dorsal epidural space on lateral view under C-arm fluoroscopy, we injected the $3 \mathrm{~mL}$ of Omnipaque 300 . If the epidural pressure checker alarmed before reaching the epidural space, the case was designated as a false positive. Eight patients were randomly assigned to each set pressure value from -8 mbar to -3 mbar with a 1 mbar interval. Therefore, 48 patients underwent cervical epidural blockade and the remaining 48 patients underwent lumbar epidural blockade with the Epi-check.

\section{RESULTS}

The mean patient age was $56.1 \pm 13.7$ years and the gender ratio did not show significant difference in each group ( $p$ value 0.543 and 0.957$)$. There were a similar number of cervical and lumbar cases (Table 1). In the cervical group, the detection rates (sensitivity) were $62.5 \%, 75 \%$, and $75 \%$ at $-8 \mathrm{mbar},-7 \mathrm{mbar}$,

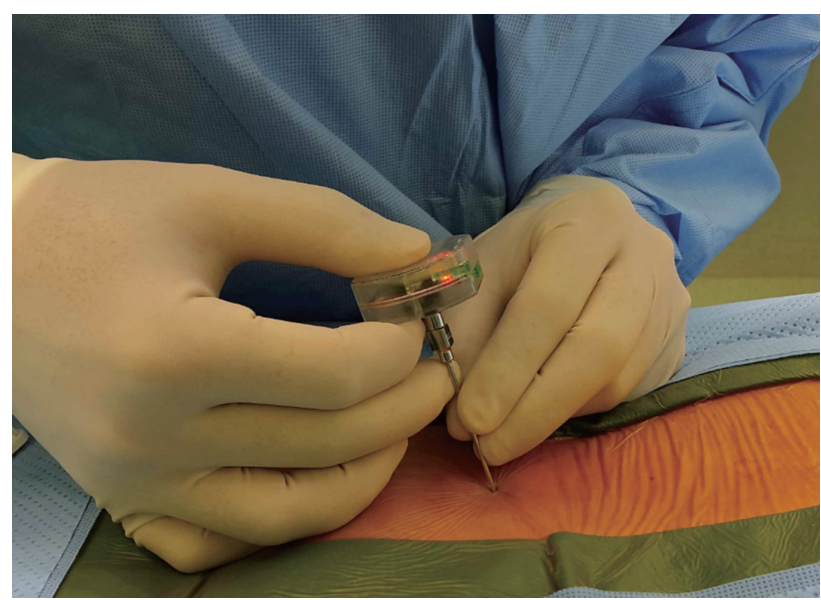

Fig. 2. Use of the Epidural pressure checker in the administration of a lumbar trans-laminar epidural block. The Epidural pressure checker alarms with light and color change from red to green once the device detects the set pressure change. 
Table 1. Patient demographics

\begin{tabular}{lccl}
\hline & $\begin{array}{c}\text { Cervical } \\
(\mathrm{n}=48)\end{array}$ & $\begin{array}{c}\text { Lumbar } \\
(\mathrm{n}=48)\end{array}$ & $p$-value \\
\hline Number of patients $(\mathrm{M}: \mathrm{F})$ & $20: 28$ & $22: 26$ & $>0.543$ \\
Age (mean) & $56.17 \pm 8.66$ & $59.3 \pm 7.93$ & $>0.957^{\star}$ \\
\hline
\end{tabular}

${ }^{*}$ chi-square test and independent t-test

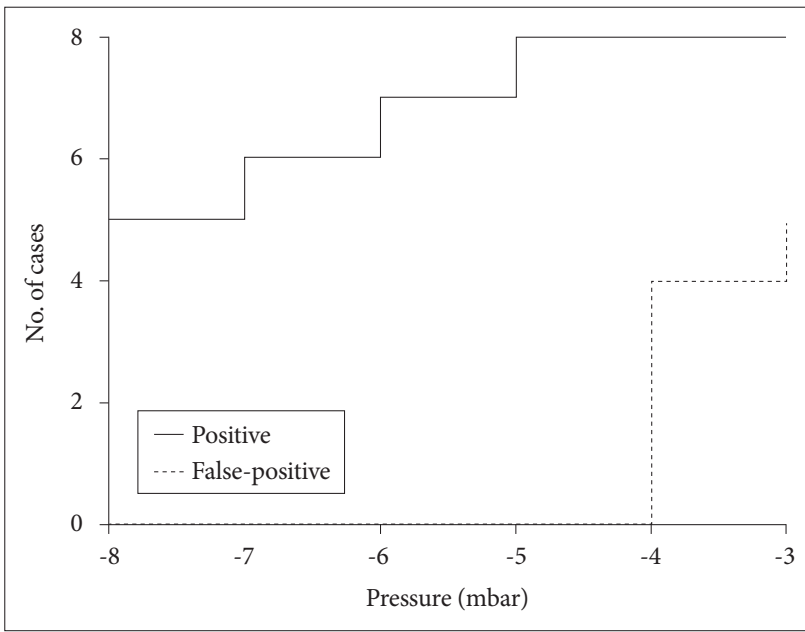

Fig. 3. Detection rate of the Epidural pressure checker in the lumbar group. A pressure threshold of -5 mbar yielded an $87.5 \%$ detection rate. However, -4 mbar showed a $50 \%$ false positive rate and -3 mbar showed a $62.5 \%$ false positive rate.

Table 2. Detection rate of the Epidural pressure checker at each pressure threshold

\begin{tabular}{lcclcc}
\hline & \multicolumn{2}{c}{ Cervical $(\mathrm{n}=48)$} & & \multicolumn{2}{c}{ Lumbar $(\mathrm{n}=48)$} \\
\cline { 2 - 3 } \cline { 5 - 6 } & $\begin{array}{c}\text { Alarm } \\
\text { (on }: \text { off })\end{array}$ & Rate $(\%)$ & & $\begin{array}{c}\text { Alarm } \\
(\text { on }: \text { off })\end{array}$ & Rate $(\%)$ \\
\hline$-8 \operatorname{mbar}(\mathrm{n}=8)$ & $5: 3$ & 62.5 & & $4: 4$ & 50 \\
$-7 \operatorname{mbar}(\mathrm{n}=8)$ & $6: 2$ & 75 & & $5: 3$ & 62.5 \\
$-6 \operatorname{mbar}(\mathrm{n}=8)$ & $6: 2$ & 75 & & $5: 3$ & 62.5 \\
$-5 \operatorname{mbar}(\mathrm{n}=8)$ & $7: 1$ & 87.5 & & $7: 1$ & 87.5 \\
$-4 \operatorname{mbar}(\mathrm{n}=8)$ & $8: 0^{*}$ & 50 & & $8: 0^{*}$ & 62.5 \\
$-3 \operatorname{mbar}(\mathrm{n}=8)$ & $8: 0^{*}$ & 37.5 & & $8: 0^{*}$ & 50
\end{tabular}

${ }^{*}$ false positive, the Epidural pressure checker alarmed with sound and light before reaching the epidural space

and -6 mbar, respectively, and $87.5 \%$ at -5 mbar. However, the epidural pressure checker showed false positives at both -4 mbar and -3 mbar. False positives did not occur when the set value was greater than -4 mbar (Fig. 3). Similar to the cervical group, the detection rates were $50 \%, 62.5 \%$, and $62.5 \%$ at -8 mbar, -7 mbar, and -6 mbar, respectively, and $87.5 \%$ at -5 mbar in the lumbar group. In addition, there were false positives at both -4 mbar, and -3 mbar (Table 2). There were no cases of dural puncture or CSF leakage with the epidural pressure checker.

\section{DISCUSSION}

Inter-laminar epidural blockade is a widely performed procedure to treat patients with spinal axial pain. The LOR tech- nique is most commonly used to detect the epidural space ${ }^{11)}$. However, this technique has some disadvantages and potential complications such as dural puncture, epidural hematoma and potentially higher failure rates with inexperienced physicians. To overcome these problems, several authors proposed modified techniques. Sawada et al. proposed that Epidrum ${ }^{\circledR}$ is useful for epidural anesthesia. It is a device that can alarm the physician on entry into the epidural space by collapse of the diaphragm, and they insisted that this device can reduce the time required for successful epidural detection ${ }^{15)}$. Todorov et al. reported that the hanging drop technique is also a feasible alternative that relies on the aspiration of fluid at the needle hub as the pressure at the needle tip decreases below the atmospheric pressure $^{18}$. This procedure relies on the presence of sub-atmospheric epidural pressure, which is very similar to the epi-check. Both work by detecting the negative pressure shift in the Tuohy needle cavity once the needle tip penetrates the ligamentum flavum. In addition, Todorov et al. reported that the time required was significantly shorter than that for the conventional LOR technique. Although we did not measure the exact time required to administer an epidural block with the Epi-check, we also noticed the time required seemed shorter than the conventional method.

In this study, we confirmed that the optimal pressure at which to detect the epidural space is -5 mbar. The epidural pressure checker set at -5 mbar pressure achieved an $87.5 \%$ success rate in epidural space detection. A previous study reported that the entering pressure of the epidural space ranged from -1 to -7 $\mathrm{cmH}_{2} \mathrm{O}^{19)}$, and Usubiaga et al. found that cervical epidural space pressure ranged from -2 to $-6 \mathrm{cmH}_{2} \mathrm{O}$ and lumbar epidural space pressure from -1 to $-6 \mathrm{cmH}_{2} \mathrm{O}^{20)}$. Notably, all of these ranges contain our value of -5 mbar. However, the positive result of the Epi-check may not indicate the "real" epidural negative pressure. Zarzuret al. reported that there is no real negative pressure in the lumbar epidural space and they insisted that it is an artifact resulting from bulging of the ligamentum flavum ${ }^{21}$. They described that prompt restoration of the ligamentum flavum after penetration of the needle tip induces the negative pressure, and the mean value of the negative pressure was -0.4 $\mathrm{kPa}$-similar to our finding for $-5 \mathrm{mbar}$. Gil and Todorovet al. insisted that the epidural pressure is more negative in the sitting position than in the lateral decubitus ${ }^{7,18}$. Therefore, the sitting position rather than decubitus position will likely increase the rate of epidural space detection.

The conventional LOR technique requires a heavy glass syringe and completely depends on one's own subjective feeling. This is a disadvantage in the hands of inexperienced physicians or residents and sometimes results in complications such as dural puncture, epidural hematoma or muscle origin pain, as well as long procedural time. Among them, the dural puncture is most common. It can lead to intractable headaches following CSF leakage and traction of the meninges ${ }^{6}$. In this study, the Epi-check helped prevent dural puncture and it was light and easy 
to handle, even for beginner physicians, and alarmed clearly with sound and light. The Epidrum ${ }^{\circledR}$ uses air as a detection tool, while the hanging drop technique uses water to detect the epidural space. On the contrary, the epidural pressure checker just detects a change in pressure and thus no material is inserted into the epidural space. Therefore, we believe that use of Epi-check can help to overcome the disadvantages of other techniques.

There are some limitations to the present study, including the small number of enrolled patients. Although 96 total patients were enrolled, there were only 16 for whom the pre-set pressure threshold was -5 mbar. We found that the optimal pressure threshold for detecting the epidural space was -5 mbar in the present study; therefore further investigations should focus on this pressure value to enhance the accuracy. The allowable electronic error of the device is also a limitation. The range of allowable error was $-0.5 \mathrm{mbar}$ to $+0.5 \mathrm{mbar}$. Therefore, $-5 \mathrm{mbar}$ could potentially become -4 or -6 mbar in a larger cohort study. The basic assumption of the present study was that there is a pressure change when the ligamentum flavum is penetrated by the needle tip. Therefore, the epidural pressure checker might not detect a pressure change in patients with weak or absent ligamentum flavum.

\section{CONCLUSION}

The optimal pressure for detecting the epidural space was -5 mbar in this study. The Epidural pressure checker is reliable, simple, and easy. It alarms upon entry into the epidural space by perceiving a pressure change and is therefore useful in administering a gentle trans-laminar epidural block as well as being safe for training inexperienced physicians. However, this device can result in false negatives or false positives in patients with an abnormal or absent ligamentum flavum. Therefore, physicians should use this device as a supplemental tool.

\section{- Acknowledgements}

This research was supported by a grant of the Korea Health Technology R\&D Project through the Korea Health Industry Development Institute (KHIDI), funded by the Ministry of Health \& Welfare, Republic of Korea (grant number: HC15C1320).

\section{REFERENCES}

1. Andersson GB : Epidemiological features of chronic low-back pain. Lancet $354: 581-585,1999$
2. Andersson GBJ : The epidemiology of spinal disorders, in Frymoyer JW (ed) : The adult spine : Principles and practice. Philadelphia : LippincottRaven, 1997, pp93-141

3. Angle PJ, Kronberg JE, Thompson DE, Ackerley C, Szalai JP, Duffin J, et al. : Dural tissue trauma and cerebrospinal fluid leak after epidural needle puncture : effect of needle design, angle, and bevel orientation. Anesthesiology 99 : 1376-1382, 2003

4. Deyo RA, Tsui-Wu Y-J : Descriptive epidemiology of low-back pain and its related medical care in the United States. Spine 12 : 264-268, 1987

5. Director MP, Manchikanti L : Preliminary results of a randomized, doubleblind, controlled trial of fluoroscopic lumbar interlaminar epidural injections in managing chronic lumbar discogenic pain without disc herniation or radiculitis. Pain Physician 13 : E279-E292, 2010

6. Fyneface-Ogan S: Anatomy and clinical importance of the epidural space, in Fyneface-Ogan S (ed) : Epidural analgesia : current views and approaches : InTech Open Access Publish, 2012, pp1-12

7. Gil NS, Lee J-H, Yoon SZ, Jeon Y, Lim YJ, Bahk JH : Comparison of thoracic epidural pressure in the sitting and lateral decubitus positions. Anesthesiology $109: 67-71,2008$

8. Kunkle EC, Ray BS, Wolff HG : Experimental studies on headache : analysis of the headache associated with changes in intracranial pressure. Arch Neurol Psychiatry 49 : 323-358, 1943

9. Lechner TJ, van Wijk MG, Maas AJ, van Dorsten FR, Drost RA, Langenberg CJ, et al. : Clinical results with the acoustic puncture assist device, a new acoustic device to identify the epidural space. Anesth Analg 96 : 1183 1187,2003

10. Lutz GE, Vad VB, Wisneski RJ : Fluoroscopic transforaminal lumbar epidural steroids : an outcome study. Arch Phys Med Rehabil 79 : 1362-1366, 1998

11. Miller RD : Miller's anesthesia. Philadelphia, PA : Elsevier Churchill Livingstone, 2005

12. Pear BL : Spinal epidural hematoma. Am J Roentgenol Radium Ther Nucl Med 115 : 155-164, 1972

13. Radhakrishnan K, Litchy WJ, O’Fallon WM, Kurland LT : Epidemiology of cervical radiculopathy. Brain 117 : 325-335, 1994

14. Robecchi A, Capra R : Hydrocortisone (compound F); first clinical experiments in the field of rheumatology. Minerva Med $43: 1259,1952$

15. Sawada A, Kii N, Yoshikawa Y, Yamakage M: Epidrum ${ }^{\circledR}$ : a new device to identify the epidural space with an epidural Tuohy needle. J Anesth 26 : 292-295, 2012

16. Sicard JA, Forestier J : Methode radiographique dexploration de la cavite epidurale par le Lipiodol. Rev Neurol 28 : 1264-1266, 1921

17. Stoll A, Sanchez M : Epidural hematoma after epidural block : implications for its use in pain management. Surg Neurol 57 : 235-240, 2002

18. Todorov L, VadeBoncouer T : Etiology and use of the "hanging drop" technique : a review. Pain Res Treat $2014:$ 146750, 2014

19. Usubiaga JE, Moya F, Usubiaga LE : A note on the recording of epidural negative pressure. Can Anaesth Soc J 14 : 119-122, 1967

20. Usubiaga JE, Wikinski JA, Usubiaga LE : Epidural pressure and its relation to spread of anesthetic solutions in epidural space. Anesth Analg 46 : 440-446, 1967

21. Zarzur E : Genesis of the 'true' negative pressure in the lumbar epidural space. Anaesthesia 39 : 1101-1104, 1984 